\title{
Leaving a Mark, Making a Difference
}

\author{
Tamar Ascher Shai
}

David Yellin Academic College of Education, Israel

Copyright $(2016$ by authors, all rights reserved. Authors agree that this article remains permanently open access under the terms of the Creative Commons Attribution License 4.0 International License

\begin{abstract}
Thirteen years after the completion of my doctoral research I located ten of the students of early childhood education who had participated in the study, in order to discern what had had a great enough impact on them as teachers-to-be, that it would find its expression even thirteen years later. The intervention doctoral program is briefly summarized, as well as the references made to this program by the participants. This paper does not present an in-depth longitudinal study, but rather a form of update on a study that, at its conclusion, suggested that the true effects of the program would probably only become apparent to the students themselves many years later. The results and conclusions of this follow-up are surprising and challenging to teacher trainers and educators alike.
\end{abstract}

Keywords Educational Belief Systems, Teacher Training, Meaningful Experiences

\section{Introduction}

"In a certain sense every experience should do something to prepare a person for later experiences of a deeper and more expansive quality. That is the very meaning of growth, continuity, reconstruction of experience."

Dewey, J. (1938) Experience and Education

In my final year as a student of education, one of my professors announced that our last class session would be a field trip. We were to spend the day on the beach together. We drove out to a distant, very private and rather deserted beach, where we were split into several smaller groups and given the assignment to create our own culture, which we were later to present to the other groups. This culture included among other things the history of our 'becoming', rituals, dress code, music and art. The day at the beach remained one of the most important, even life changing experiences that I had during my own studies.

During that day at the beach, when instructed to create our own culture, we were strongly encouraged to use the fabulous surrounding nature as a focus for inspiration. The notion of using nature as an ally in this teaching venture was to become an important part of my own intervention program with my students, as I will describe later.

There is a strong connection between the structure of most teacher training programs and the spirit of education in the public school system. Most models for teacher training that one encounters today reflect the problem spots existing in many areas of today's education, as described beautifully by Abbs [1] (1994:2):

"Education itself has fallen into the hideous black hole of unmeaning... [it] has lost any sense of the transcendent ends which, when it is true to its own nature, it willingly and lovingly serves... [education today speaks] the language of visionless control..."

This predicament was described by several others as well, Hicks and Holden [2] (1995) described it as a "loss of societal direction and purpose" that arise from the fact that we "lack guiding visions for the future", while Gardner [3] (1995) noted how "a sense of calling is disappearing".

It was this sense of the loss of vision, and my impression that students training to become teachers were not clear about their educational belief systems, that led me to my original research. In the course of one academic year I tested my assumptions regarding possible ways of affecting students' belief systems by applying an intervention program in which my class of twenty-two students took part (Ascher [4], 2001). I was hoping to find enough evidence of at least initial or partial change in the way my students thought about education, that would allow me to conclude and suggest some general guidelines for teacher training of a slightly different sort. It was clear to me though, that more definite signs of my program having had any actual impact on my students would become evident only many years later, when their experiences had settled into their emotional and mental structures deeply enough to affect their belief systems.

This paper wishes to present the follow up research that took place thirteen years after my above noted doctoral study. Since I could not locate all the students from that particular class, I invited a group of ten students, in order to hear about the development of their professional lives since then. I was in search for signs that might suggest that my special program had in fact influenced them in some way, leaving a mark on their lives. 


\section{The Program}

In my search for ways to help my students recognize and develop their educational beliefs in the course of their teacher training, I designed a special intervention program consisting of three main parts: "guided imagery sessions", "debates", and "extraordinary learning experiences". I believed that each one of these parts would play a role in reflecting the students' developing beliefs, as well as have some influence on them in the course of this development.

\section{Guided Imagery Sessions}

The sessions, which took place once almost every week, were aimed at helping the students practice the skill of imagining, in order to enhance the students' ability to partake in the developing of a mental picture of what may be the ideal educational setting and program. While part of the guided imagery sessions in fact dealt with the imagining of situations that had never actually been experienced, a substantial part of the sessions dealt with memories from the past. As Lortie [5] (1995) along with several other researchers had noted, students arrive to their teacher training programs already well equipped with their own rich repertoire of internalized teacher-models (or educational belief systems), which they have collected and assembled during their long experience of being pupils. Before one can begin developing or possibly changing these models, they need to be brought into the students' consciousness. The practice of accessing different areas of their subconscious was expected to facilitate this process.

\section{Debates}

This part of the program intended to tackle the issue of affecting belief systems from yet a different angle. The debates were classes built around confronting theories and educational beliefs of known thinkers in educational philosophies throughout the ages. In the course of the year we studied the educational theories from as early as the ancient Greek, such as Sappho and Socrates, all the way through history, ending with the era of the critics such as Montessori. Furthermore, the students met guest speakers who presented and discussed their own belief systems with the class. The confrontation with other people's belief systems, past or present, was an activity which was aimed at broadening the students' horizons, presenting them with different models of thinking about education, and showing how these models were embedded in history - personal and universal alike.

\section{Extraordinary Learning Experiences}

While the guided imagery sessions focused on achieving personal insights, a higher degree of consciousness and reflection in order to help the students more successfully confront their already existing belief systems, this part of the intervention program dealt more with the subject matter of early childhood education. The contexts in which these learning situations took place were purposely out of the ordinary, in the hope of creating learning experiences so different from, and sometimes even contrary to what the students had experienced in their own lives as pupils, as to cause a certain degree of cognitive disequilibrium. This is described by Piaget as being a serious step towards intellectual growth (Cowan [6], 1978). Going along with the assumption that educational belief systems have very firm mental structures which are not easily changed, it seemed necessary to 'attack' the challenge of influencing and possibly changing these belief systems by direct confrontation. These confrontations were expected to cause enough cognitive disequilibrium as to require some degree of reorganization of thought, hopefully resulting in change.

In this part of the program I organized special field trips, taking my students to the beach in order to study and rediscover the joys and variations of play, I took them to the forest in the attempt to immerse them into the world of stories and fairytales, and a day in the desert presented us with an opportunity to reinvent ourselves as educators of the future. An early morning trip to observe the sunrise gave us an example of how young children discover the world, and the end of the year we concluded in watching the sunset together. In Nespor's [7] (1987:320) words, I was dealing with some crucial experience or even some particularly influential teacher who may produce "a richly detailed episodic memory which later serves (...) as an inspiration and a template for [her] teaching practices."

I was particularly invested in this third part of the program, the reason lying in my own history of an extraordinary learning experience I had had as a student, in fact exactly thirteen years prior to my year of research.

\section{Methodology and Methods}

"Action Research is a form of self-reflective enquiry undertaken by participants (teacher, students or principals, for example) in social (including educational) situations in order to improve the rationality and justice of (a) their own social or educational practices, (b) their understanding of these practices, and (c) the situations (and institutions) in which these practices are carried out."

McNiff [8] (1988:2) quoted this definition by Carr and Kemmis [9] (1986), and with that described the reason and circumstance of my intervention program. Zeni [10] (1998) discussed the type of research done by teachers as 'insiders', where they document their own practice using tools of qualitative research such as case studies and autobiography, both of which played a role in my research as well. Zeni also noted in which ways action research is different from teaching: Action research involves systematic documentation and data gathering, more self-reflection in writing, and addresses with its results a wider audience, which would include presentations to colleagues, collaboration with other professionals and publication of the 
findings. The above described intervention program took place in the context of an action research study, where my work as a pedagogical advisor (teacher trainer) underwent several changes, with the goal of deepening the effect that my course had on my students' development and future practice.

In the original research, the methods for data collection included the use of questionnaires, journals (both my own as well as those kept by the students), observations, photographs and interviews. The follow up research that is presented in this paper was however limited to an interview only. This follow up research was not conducted as a developed, in-depth longitudinal study, but rather as a more casual 'update' with regard to possible long-term outcomes of the original study.

The interview contained characteristics of what Cohen and Manion [11] (1994) call "structured interviews" as well as "non-directive interviews". The interview was structured in that the questions that I asked the students were planned and formulated in advance, and were posed to each student in the same way. Nonetheless, the questions were very open-ended, leaving room for spontaneity and the free and full expression of subjective feelings, thus resembling the nature of the non-directive interview. In the course of the interviews many of the former students volunteered so much information in response to the opening question, that the following questions often became futile.

\section{Results and Discussion}

At the outset of this study, my focus was to discover which experiences or parts of my doctoral program had most affected my students, to the point where they might even identify those that had left their mark on their professional lives until this day. As expected, the first two parts of the program were mentioned only occasionally and almost in passing, while in fact the former students, who for the most part had become teachers, did describe in much more detail the impact that some of our field trips had made on them. However, they also noted two additional types of 'meaningful experiences' that proved to have left a mark on their lives. Aside from the field trips, they noted what I will continue to define as "teaching moments". They related to regular day-in day-out teaching opportunities. My surprise and slight disappointment revolved around the fact that these impromptu incidents for teaching were mentioned even more frequently by my former students than the eagerly planned outings.

And finally, the last type of meaningful experience was put into the context of what I define as "impressions made as a person". Even though the number of comments made in this category is smaller than the above, this category strikes me as the most important of the three, since it emphasizes the notion that 'who you are' is far more important than 'what you do', when it comes to education.

The type of experience that was mentioned most during the interviews was the 'teaching moments'. These included the lessons that had taken place for the most part in their field work settings, at times when I came to observe them and reflect with them upon their actual, concrete experiences with young children. This is an important point to notice, for these meetings are not planned or prepared in advance, but rather deal with the 'here and now' of whatever is happening in the students' real 'teaching life', and not with any educational theory or philosophy. One student recalled "you taught me to think positively. When you'd come and see me [in the field placement], you would ask what had happened, and I would start by telling you something that was problematic. You made me change my thinking... you would say "start with something positive". I always do that now. I never start a conversation with a parent without saying something positive first." I can see how such immediate, on the spot feedback would be meaningful, and how later in their professional lives as teachers such moments would make new appearances, as their daily experiences bring back their memories. Often, in thinking back on their studies, students have noted how their field experiences were the most meaningful part of their professional development.

A fairly close runner up to the 'teaching moments' was the 'extraordinary learning experiences' (the field trips). I would dare say that these types of memories have the make-up of educational beliefs, as opposed to the previous memories, which mostly focused on ways of working with children. Through these memories they were telling of something very personal that they had experienced. One student, for example, immediately began to retell "the beach was the best place in order to learn about the sand box... sitting and understanding the value of it all.... All throughout my first year, when I was teaching kids, I was thinking about the beach, again and again, when the kids went out into the yard... I think about it all the time...". This finding certainly strengthened my assumption that these types of learning situations were well worth the effort put into planning and executing them. It appears that I had in fact managed to touch a deeper, belief-related part of my students' minds in a way that lasted well past the actual experience.

In the category of "impressions made as a person" I sense great weight. As mentioned before, the other two categories were brought up more frequently by my former students; I was particularly touched by the fact that the character and approach of the person standing before the students would leave such a strong impression on their lives. One of the former students shared with me "your personal story, about how you broke all social norms and did what was good and right for you - that surely wasn't easy for you, but in the class you gave the feeling that in the end everything works out, slowly, after going through a process, everything becomes ok." But other professors were mentioned as well, "the science teacher will not be forgotten, ever, until the day I die. What is important in her approach is that students weren't just a number. It's a more personal approach, more supportive, I take that with me." These memories are of 
course not necessarily surprising, since most of us can remember and point out people in our personal histories, who have left their marks on our lives. But in the context of developing a program around educational belief systems, I seemed to have overlooked the importance of the teacher her/himself and her character and spirit, as so very influential. Only six of my ten past students had produced this type of memory, but I do believe that it is the quality that counts, and less so the quantity. The memories of people whom they felt had touched their lives in irreversible ways are expressed emotionally and even passionately, and similarly to the previous category of "extraordinary learning experiences", the way most of these memories are presented show a connection to deeply held beliefs.

\section{Conclusions}

What kind of experience can hold the power to cause change in a person's belief system? Dewey [12] (1938:40) gave very specific points to watch out for, when thinking about and planning such a learning experience:

"A primary responsibility of educators is that they not
only be aware of the general principle of shaping of
actual experience by environing conditions, but that
they also recognize in the concrete what surroundings
are conducive to having experiences that lead to
growth."

This point made by Dewey affirmed one particular action that I took in creating what I hoped would be meaningful learning experiences for my students. I found that, once I took them outside of the physical surroundings of the College and into different spaces in nature, just as my own professor had done with us at the time, I was increasing my chances of creating something new, and adding meaning that previously had not been experienced, to the learning situation.

Britzman [13] (1991:34) discussed Dewey's ideas,

"The difference between lived experience and mere circumstance is our capacity to bestow experience with meaning, be reflective, and take action."

Tripp [14] (1993:8) calls these types of subjective experiences 'critical incidences', and discusses the need for reflection upon what has occurred:

"Critical incidences are created - produced by the way we look at a situation: it's an interpretation of the significance of an event. We have to ask what happened, and what caused it to happen... [Searching for] the deeper structures that produced the incident."

In concluding my doctoral research, I was not really able to discern the effects that my program had had on my students, but I was acutely aware that if something meaningful had in fact taken place, this would be evident in the future, just as it had become for me.

As opposed to typical longitudinal research, this paper fulfills the purpose of closing the circle of my past research, allowing insight into possible long-term effects that educational intervention might carry.

I admit that I was hoping to get confirmation that in fact my specific doctoral program had achieved the effect that had been intended. I was expecting to discover that my assumptions regarding effective ways of working on students' educational belief systems were well founded, and that I might state my own theory around extraordinary learning experiences with stronger conviction and even proof. My main and most critical finding however is that the notion of "meaningful experience" is a very subjective one. Based on my own past experience, I had assumed that connecting with nature was the key to teaching in deep and meaningful ways. However, in questioning my past students with regard to the learning experiences that they remembered and that had influenced them as teachers, I came to realize how each former student described a very personal memory of meaningful experiences, and that there is no one definition that fits this concept.

While experiences during field trips were certainly mentioned quite frequently, the students tended to remember many meaningful "teaching moments", situations in which I either taught something formally in class, or comments that I had made in relation to experiences they had had during their field work. "Impressions made as a person" left me with the strongest insight, being that 'who we are' is possibly more important than 'what we say or do', and it is the way in which we relate to our students, and the way in which we present ourselves as human beings and as professionals, that will leave the strongest mark on those we share our teaching moments with. As I mentioned at the outset of this paper, Nespor [7] had suggested that while the issues I was dealing with could be connected with some crucial experience, they are also likely to be related to some particularly influential teacher who would become the inspiration for the students' developing educational belief system.

\section{REFERENCES}

[1] Abbs P. The Educational Imperative: A Defense of Socratic and Aesthetic Learning. Falmer Press; 1994.

[2] Hicks D. and Holden C. Visions of the Future. Trentham Books Limited; 1995.

[3] Gardner H. Creativity: new views from psychology and education. Delivered to the Society, The Arts Council of England; Jan. 4. 1995.

[4] Ascher T. The Role of Educational Belief Systems in Teacher Education. Sussex: Doctoral thesis submitted to the University of Sussex; 2001.

[5] Lortie DC. Schoolteacher: A Sociological Study. University of Chicago Press; 1975.

[6] Cowan PA. Piaget with Feeling: Cognitive, Social, and Emotional Dimensions. Holt, Rinehart and Winstson; 1978. 
[7] Nespor J. The role of beliefs in the practice of teaching. J Curr Stud. 1987; 19(4): 317-328.

[8] McNiff J. Action Research: Principles and Practice. Macmillan Education Ltd.; 1988.

[9] Car W. and Kemmis S. Becoming Critical: education, knowledge and action research. Falmer Press; 1986.

[10] Zeni J. A Guide to Ethical Issues and Action Research. Educ Action Res. 1998; 6(1).
[11] Cohen L. and Manion L. Research Methods in Education. Routledge; 1994.

[12] Dewey J. Experience and Education. Kappa Delta Pi, Macmillan; 1938.

[13] Britzman DP. Practice makes Practice: a critical study of learning to teach. Albany: State University of New York Press; 1991.

[14] Tripp D. Critical Incidents in Teaching. New York: Routledge; 1993. 